\title{
SERUM REPRESSOR ELEMENT-1 SILENCING TRANSCRIPTION FACTOR LEVELS IN ALZHEIMER'S PATIENTS FROM A NATIONAL INSTITUTE OF HEALTH IN MEXICO CITY, ELDERLY AND YOUNG CONTROLS
}

\author{
Francisco L. Ramírez-Cuapio ${ }^{1,2}$, Mónica A. Torres-Ramos ${ }^{3}$, Marisol Orozco-lbarra ${ }^{4}$, \\ ISAAC ACOSTA ${ }^{1}$, AND ANA L. SOSA-OrTIZ ${ }^{1 *}$ \\ 1Dementia Laboratory, Instituto Nacional de Neurología y Neurocirugía Manuel Velasco Suárez (INNNMVS), Mexico City; \\ 2Master's Program in Chemical-Biological Sciences, Escuela Nacional de Ciencias Biológicas, Instituto Politécnico \\ Nacional, Mexico City; ${ }^{3}$ Neuroscience Peripheral Unit, INNNMVS/Universidad Nacional Autónoma de México, \\ Mexico City; ${ }^{4}$ Laboratory of Molecular and Cellular Neurobiology, INNNMVS, Mexico City, Mexico
}

\begin{abstract}
Background: Decreased levels of repressor element-1 silencing transcription (REST) factor in the brain, plasma, and neuronderived exosomes are associated with Alzheimer's disease (AD). Objective: The objective of the study was to test the viability of serum REST as a possible blood-based biomarker for AD, comparing serum REST levels in AD patients from a National Institute of Health in Mexico City (with different levels of severity and comorbidities), with elderly controls (EC) and young controls (YC). Methods: We used an enzyme-linked immunosorbent assay to determine serum REST levels in AD patients $(n=28)$, EC $(n=19)$, and YC $(n=24)$; the AD patients were classified by dementia severity and comorbidities (depression and microangiopathy) using clinimetric tests and magnetic resonance imaging. Results: Mean serum REST levels did not differ between AD patients, EC, and YC. The severity of AD and the presence of depression or microangiopathy were not associated with serum REST levels. Conclusion: Our results differ from previously published patterns found for plasma and cerebral REST levels. Free serum REST levels may not be a viable AD blood-based biomarker. (REV INVEST CLIN. 2021;73(1):17-22)
\end{abstract}

Key words: Aging. Blood-based biomarkers. Dementia. Non-invasive diagnostic tools. Neural-restrictive silencer factor. RE-1 silencing transcription factor.

\section{INTRODUCTION}

The World Health Organization has stated Alzheimer's disease (AD) as a public health priority due to its increasing frequency ${ }^{1,2}$. The most extensively used AD biomarkers are based on neuroimaging methods and cerebrospinal fluid measures of amyloid-beta and tau proteins ${ }^{3}$. Given the cost and relative invasiveness
*Corresponding author:

Ana L. Sosa-Ortiz

E-mail: drasosa@hotmail.com
Received for publication: 04-03-2020

Approved for publication: 22-06-2020

DOI: $10.24875 /$ RIC. 20000089

0034-8376 / (c) 2020 Revista de Investigación Clínica. Published by Permanyer. This is an open access article under the CC BY-NC-ND license (http://creativecommons.org/licenses/by-nc-nd/4.0/). 
of these tests, there exists a growing interest in finding cheaper, more accessible, and less invasive alternatives. Blood-based biomarkers are one such alternative, as they allow for enhanced evidence of the AD pathophysiological process, particularly in the earlier stages of $A D$ progression ${ }^{4}$. One of these potential biomarkers is a protein known as the repressor element-1 silencing transcription (REST) factor.

REST is present in cerebral tissue and has been related with relevant neuroprotective functions, cognitive preservation, and longevity 5,6 ; it functions as a gene repressor in both central and peripheral tissues during physiological and pathological events throughout life $\mathrm{e}^{7,8}$. REST can be detected peripherally in blood cells ${ }^{9,10}$, in neuron-derived exosomes (NDEs) ${ }^{11,12}$, and plasma ${ }^{13}$, but there exists a knowledge gap regarding REST levels in serum. Decreased brain ${ }^{5}$ and plasma ${ }^{13}$ REST levels are linked to $A D$, and there is evidence of an association between REST found in NDE and cognitive impairment ${ }^{11,12}$.

Aiming to test the viability of serum REST as a possible blood-based biomarker for AD, we compared serum REST levels among AD patients, from a National Institute of Health in Mexico City with elderly controls (ECs) and young controls (YCs). Patients were grouped according to Alzheimer's severity, as well as whether they presented cerebral microangiopathy, a disease that affects the brain microvasculature due to several pathological processes and etiologies ${ }^{14}$, or depression, both frequent $A D$ comorbidities ${ }^{15,16}$.

\section{METHODS}

\section{Study design and population}

This work is an observational, case-control study in Mexico City. We reviewed in a tertiary level hospital (Instituto Nacional de Neurología y Neurocirugía, Manuel Velasco Suarez) records from 88 AD patients attending to the dementia clinic from January 2016 to August 2016. Of these (after excluding the patients who did not meet the inclusion criteria, those who died or could not be contacted), we invited the remaining $40 \mathrm{AD}$ patients, to participate in this study as potential participants; of them, 6 did not accept to participate and 6 that accepted were eliminated later due to technical difficulties related with fasting, blood withdrawal, or a mixed dementia diagnosis. At the end, we included in the AD group 28 patients, 60 years of age or older, with clinical diagnosis of probable AD, according to the National Institute of AgingAlzheimer's Association criteria ${ }^{17}$, constituting a response rate of $70 \%$. In addition, 29 older adults, aged 60 years or older, without cognitive impairment, from a nursing home (Foundation for Human Promotion) and a human development center (CreeSer), both located in Mexico City, Mexico, were invited and all of them accepted to participate in this study; of these, 19 met the inclusion criteria, integrating the EC group. Finally, 29 bachelor students, aged $20-30$ years old, were invited and all of them accepted to participate in this study; of these, 24 fulfilled the inclusion criteria and were recruited as YCs. We excluded from the study any individual who presented a primary psychiatric or neurological disease (other than AD, depression, and microangiopathy, in the case of $A D$ patients), a significant systemic disease (particularly cardiac and neoplastic diseases), or an uncontrolled metabolic disease (such as hypertension, diabetes, or hypo and hyperthyroidism).

Sociodemographic characteristics for each group are described in table 1 .

\section{Cognitive and clinical measurements}

For all groups, we assessed global cognitive function using the mini-mental state examination ${ }^{18,19}$, scoring cognitive impairment with values below 24 . We classified cognitive functioning of EC and AD patients by grouping individuals into four classes, using the Clinical Dementia Rating (CDR) ${ }^{20}$ : no cognitive impairment $(C D R 0=E C)$, mild $A D(C D R 1)$, moderate $A D$ ( CDR 2), and severe $A D$ (CDR 3). CDR raters were previously certified by the Brief Training and Reliability Protocol for the CDR - CDR online training system, offered by the Knight AD Research Center (Knight ADRC) Memory and Aging Project of the School of Medicine of the Washington University (St. Louis, Missouri, USA). We defined depression in YC with scores of 17 or higher using the Beck Depression Invento$\mathrm{ry}^{21,22}$, whereas EC and patients with mild and moderate $A D$ were evaluated with the Geriatric Depression Scale ${ }^{23,24}$, considering depression with scores above ${ }^{5}$. For patients with severe $A D$, we identified depression with scores above 10, using the Cornell Scale for Depression in Dementia ${ }^{25}$. Microangiopathy data were 
Table 1. Sociodemographic characteristics and total protein levels by group

\begin{tabular}{lcccc}
\hline Group $(\mathrm{n})$ & $\begin{array}{c}\text { Female/male } \\
\mathrm{n}(\%)\end{array}$ & Age (years) & $\begin{array}{c}\text { Education } \\
(\text { years })^{1}\end{array}$ & $\begin{array}{c}\text { Total protein levels } \\
(\mathrm{mg} / \mathrm{mL})^{1}\end{array}$ \\
\hline YC $(\mathrm{n}=24)$ & $14(58 \%) / 10(42 \%)$ & $23.1 \pm 0.4$ & $16.7 \pm 0.3$ & $80.7 \pm 2.0$ \\
EC $(\mathrm{n}=19)$ & $9(47 \%) / 10(53 \%)$ & $73.6 \pm 8.0$ & $13.5 \pm 1.3$ & $84.8 \pm 2.4$ \\
AD $(\mathrm{n}=28)$ & $15(54 \%) / 13(46 \%)$ & $74.7 \pm 1.3$ & $6.0 \pm 1.0$ & $79.7 \pm 2.1$ \\
\hline
\end{tabular}

${ }^{1}$ Data are expressed as mean \pm the standard error of the mean (SEM), AD: Alzheimer's disease; EC: elderly control; YC: young control.

obtained from clinical records, issued by the neuroimaging department, as part of the neuroimaging studies used for supporting $A D$ diagnosis, specifically from magnetic resonance imaging (MRI) reports. MRI diagnosis of microangiopathy in all AD patients was determined by the presence of white matter hyperintensities on T2-weighted sequence, using the Fazekas scale $^{26}$, a visual rating scale that classifies, in either periventricular or deep white matter regions, the white matter lesions (grading from 0 , or absence of lesions, to 3 ), depending on its size and confluence. For this study, we included in the AD with microangiopathy group, all patients with a Fazekas scale above 1 .

\section{Blood collection and processing}

Blood samples were collected and processed according to guidelines for the standardization of pre-analytical variables for the study of $A D$ blood-based biomarkers ${ }^{27}$. We requested participants fast for at least $8 \mathrm{~h}$ before sample collection.

\section{Total protein and REST quantification}

Serum protein levels were determined using the Lowry assay and were expressed as $\mathrm{mg} / \mathrm{ml}^{28}$. Serum REST levels were determined using an enzyme-linked immunosorbent assay (ELISA) commercial kit (MBS9354282, MyBiosource, Inc., San Diego, CA, USA) following the manufacturer's instructions. Data were expressed as $\mathrm{pg}_{\text {REST }} / \mathrm{mg}_{\text {total protein }}$.

\section{Statistical analysis}

All concentration measures are expressed as the mean \pm standard error of the mean. We carried out comparisons between $A D, E C$, and YC in total protein levels and serum REST levels, using Student's t-tests or one-way analysis of variance (ANOVA) as appropriate. $p<0.05$ was considered statistically significant.
We used STATA software (version 14.1, StataCorp LLC, College Station, TX, USA) to all analyses and for calculating the power of our recruited sample.

\section{RESULTS}

We found no difference $(F=1.43,2 \mathrm{df}, \mathrm{p}=0.247$ ) between serum total protein levels across YC, EC, and AD (Table 1). Likewise, we found no difference $(p=0.243)$ in serum REST levels between YC $(\mathrm{n}=24,47.9 \pm 8.0 \mathrm{pg} / \mathrm{mg})$ versus $\mathrm{EC}(\mathrm{n}=19,36.5 \pm$ $4.0 \mathrm{pg} / \mathrm{mg}$ ), nor between $E C$ versus $A D$ patients $(n=28,53.5 \pm 8.1 \mathrm{pg} / \mathrm{mg}, \mathrm{p}=0.107)$ as shown in figure $1 \mathrm{~A}$. We found no significant differences according to $C D R(F=2.37,3 \mathrm{df}, \mathrm{p}=0.084)$ between EC mean serum REST levels and AD patients among severity groups (CDR1: $\mathrm{n}=6,77.7 \pm 27.3 \mathrm{pg} / \mathrm{mg}$, CDR2: $\mathrm{n}=15,43.8 \pm 8.3 \mathrm{pg} / \mathrm{mg}$, and CDR3: $\mathrm{n}=7$, $53.6 \pm 13.3 \mathrm{pg} / \mathrm{mg}$; Fig. 1B). We also analyzed mean serum REST levels of AD without depression ( $n=21$, $59.6 \pm 9.9 \mathrm{pg} / \mathrm{mg}$ ) compared to AD with depression $(\mathrm{n}=7,35.1 \pm 10.6 \mathrm{pg} / \mathrm{mg}, \mathrm{p}=0.193$; and they did not differ significantly, Fig. 1C). Similarly, we found AD mean serum REST levels without microangiopathy $(n=18,48.0 \pm 10.8 \mathrm{pg} / \mathrm{mg})$ did not differ significantly compared to $A D$ with microangiopathy $(n=10,63.4 \pm 11.7$ pg/mg, $p=0.370$; Fig. 1D). Considering the observed differences in serum REST levels between AD and EC (17.01 pg/mg), with an assignment of 1.42, an alpha of 0.05 and the means and standard deviations described above, the statistical power of our comparison was $55.75 \%$.

\section{DISCUSSION}

Given the role of REST as a neuroprotector ${ }^{5}$, the previously found differences in plasma and brain tissue REST levels in different age groups ${ }^{5}$, and the 
Figure 1. Serum REST concentrations. (A) We found no difference $(p=0.107)$ in serum REST levels between AD patients $(n=28,53.5 \pm 8.1 \mathrm{pg} / \mathrm{mg})$ and $\mathrm{EC}(\mathrm{n}=19,36.5 \pm 4.0 \mathrm{pg} / \mathrm{mg})$ nor between $\mathrm{EC}$ and $\mathrm{YC}(\mathrm{n}=24,47.9 \pm 8.0 \mathrm{pg} / \mathrm{mg}, \mathrm{p}=0.243)$. (B) We found no difference $(F=2.37,3 \mathrm{df}, \mathrm{p}=0.084$ ) between EC serum REST levels and AD patients ranked by CDR as mild (CDR1: $\mathrm{n}=6,77.7 \pm 27.3 \mathrm{pg} / \mathrm{mg}$ ), moderate (CDR2: $\mathrm{n}=15,43.8 \pm 8.3 \mathrm{pg} / \mathrm{mg}$ ), and severe (CDR3: $\mathrm{n}=7,53.6 \pm 13.3 \mathrm{pg} / \mathrm{mg})$. (C) We found no difference $(p=0.193)$ in serum REST concentration between AD patients with $(n=7,35.1 \pm 10.6 \mathrm{pg} / \mathrm{mg})$ and without depression $(n=21 ; 59.6 \pm 9.9 \mathrm{pg} / \mathrm{mg})$, and $(D)$ no difference was found $(p=0.370)$ in serum REST concentration between AD patients with $(n=10,63.4 \pm 11.7 \mathrm{pg} / \mathrm{mg})$ and without microangiopathy $(\mathrm{n}=18,48.0 \pm 10.8 \mathrm{pg} / \mathrm{mg})$. The horizontal line in each cluster represents the mean \pm standard error of the mean (SEM). REST: repressor element-1 silencing transcription factor; AD: Alzheimer's disease; EC: elderly control; YC: young control; CDR: Clinical Dementia Rating.

A

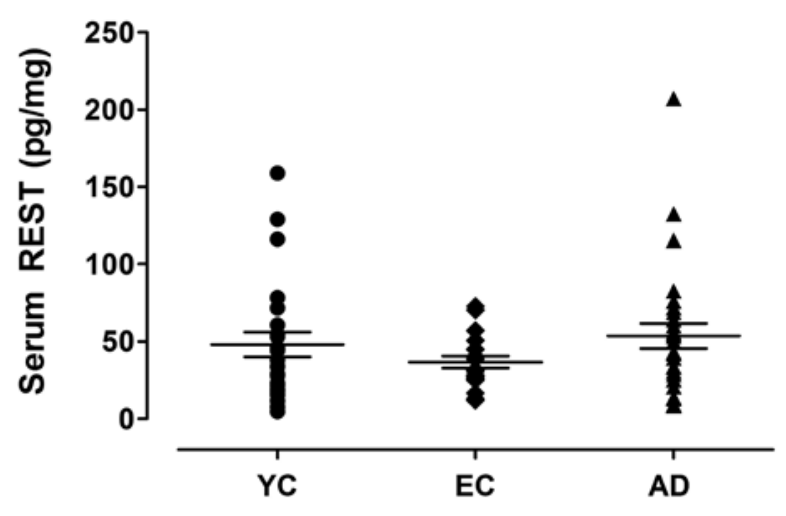

C

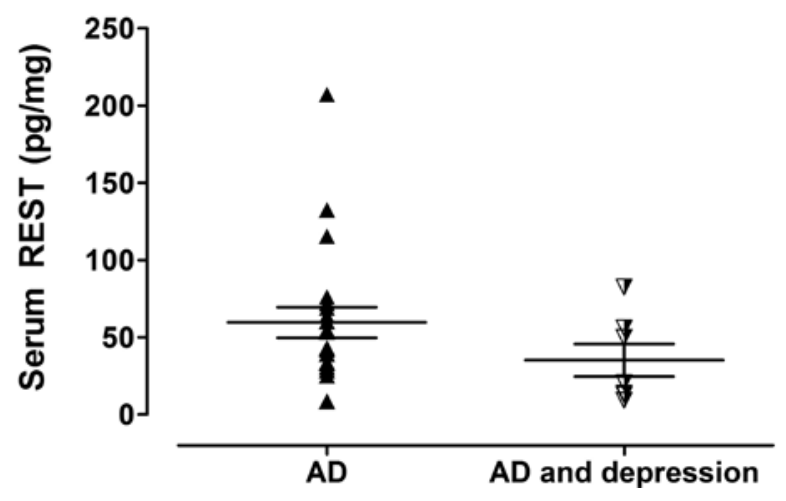

importance of finding less intrusive and less expensive ways to diagnose $A D$, our goal was to test the viability of serum REST levels as a possible blood-based biomarker for patients with AD. We tested serum REST levels because the serum is the easiest to obtain, and the most commonly tested blood component. In addition, we expected serum REST concentrations to be high because REST in plasma is found in free form (not bound) ${ }^{13}$, and this, in turn, should make routine REST detection easier in practice. However, we found no difference in serum REST levels across our groups. Our results show that measuring free serum REST concentrations does not allow the detection of
B

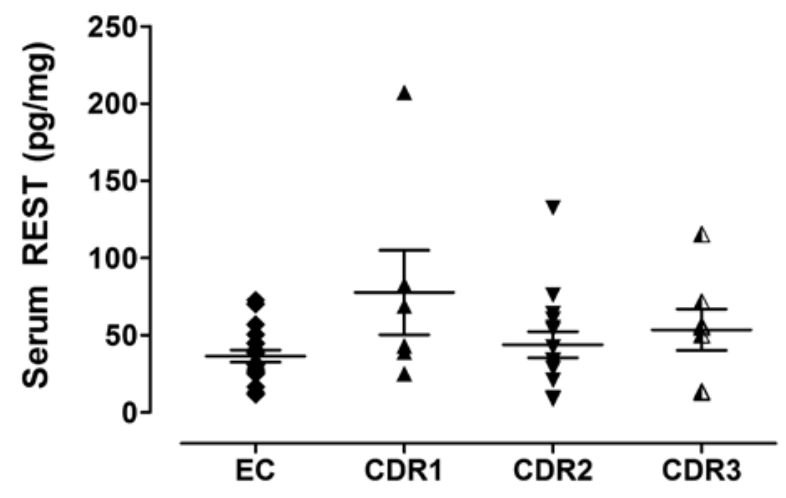

D

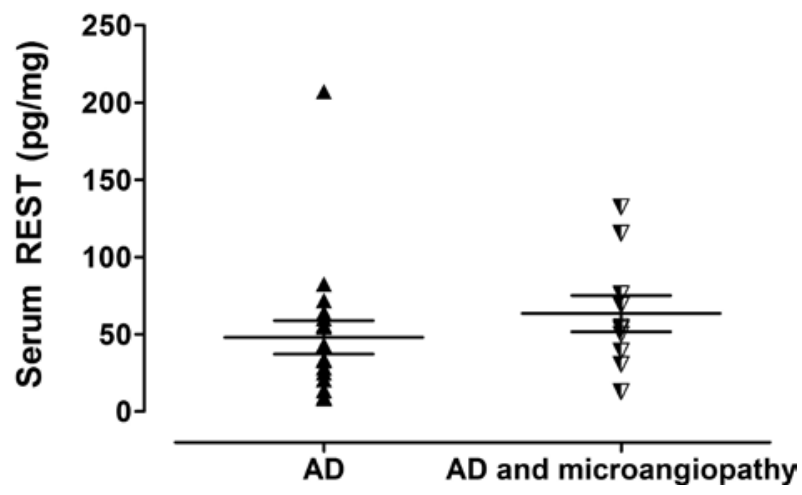

$A D$ nor to differentiate the severity of $A D$ patients, then serum REST levels are not an adequate bloodbased biomarker for AD. Moreover, our test was unable to differentiate comorbidities or allows us to detect the aging process through the blood.

Our results are surprising in that they differ from previous studies that found differences between REST levels in cerebral tissue 5 or blood ${ }^{11-13}$ in $A D$ patients and EC.

Some of the factors that may contribute to this are (i) the blood component in which REST is measured 
(serum vs. plasma) ${ }^{13}$ as it might be possible that each component contains a different concentration of REST. Furthermore, Asthon et al. (2017) pretreated plasma samples with Tween-20 (4\% v/v), aiming to release REST within extracellular vesicles. (ii) The biological component in which REST travels in the blood (NDE vs. free blood REST) as it is challenging to identify the origin of REST in free blood, unlike in NDE ${ }^{11,12}$; (iii) the ethnicity of participants, as this widely varies between the studies and it is complicated to conclude if some biological factors related to race may influence the results; (iv) the ELISA kit used, since the detection of the four different isoforms of REST could vary between the kits, altering the final concentration of REST; ( $v$ ) the severity of AD patients, while other studies focus on mild or moderate $A D^{11,12}$, ours includes patients with mild-to-severe AD. The above take relevance as it has been previously demonstrated that REST levels are related to cognitive function ${ }^{5}$ and the stage of development of $A D^{12}$; (vi) a possible contribution of peripheral blood cells, before centrifugation, to REST blood levels, since it has been shown that changes in REST expression, or its binding to the repressor element-1 (RE-1), in blood cells are a peripheral reflection of brain diseases such as Huntington and depression ${ }^{9,10}$.

We found less dispersion in EC serum REST levels than in those of $A D$ patients and YC. Given that, REST activity and DNA (deoxyribonucleic acid) binding are known to be higher in EC cerebral tissue than in that of $A D$ patients and $Y C^{5}$, the dispersion found in $A D$ and YC serum REST levels may be a peripheral reflection of free/not-bound-to-DNA cerebral REST.

As we mentioned, our results may have been influenced by the presence of various REST isoforms in the blood ${ }^{29}$; the ELISA kit we used allows the detection of two out of four known isoforms (isoforms 1 and 4). Furthermore, REST levels in the bloodstream may be variable, as it has been reported for other molecules like $\beta$-amyloid which fluctuates over the day ${ }^{30}$, considering that REST activity varies from one peripheral tissue to another, up- and downregulated genes in different organs to maintain structural and physiological functions $^{31,32}$. Thus, longer-term studies that do not rely on a single measure may offer a different outcome.

Our study raises new questions, the most pressing of which is why plasma REST levels diminish in $A D$ patients while serum REST levels do not. The answer may lie in the way REST binds to other molecules in the blood, whether REST travels from peripheral tissues to the blood, REST isoform detection, or overall REST level variability and fluctuation even throughout the day. Although some studies have reported significant differences in levels of different peripheral biomarkers, it would also be useful to explore the discriminating capacity of these measurements for subjects at risk of $A D$, to have an alternative that can be easily implemented in the clinical setting.

Among the limitations of our study are (i) the fact that patients were recruited from a tertiary level hospital, therefore, these results might be difficult to generalize to other populations; (ii) a possible bias of a crosssectional study versus follow-up studies, as it might be possible for REST, like plasma $\beta$-amyloid, to fluctuate over the time, as stated previously ${ }^{30}$; (iii) the low statistical power (55.75\%) of our comparisons, and (iv) the relatively small sample size for each category. The sample size needed to test the effect observed in this study is of 104 participants, 62 AD, and 42 EC.

Finally, there are several pieces of evidence supporting that REST is associated with the brain's stress response and in the downregulation of genes that mediate excitatory neurotransmission. All of these actions operate in favor of cognitive preservation and longevity ${ }^{5}$, these facts encourage to continue with the generation of knowledge about REST and its cooperation with multiple active agents related to its epigenetic activity $^{8}$. Other important evidence is the increase in plasma REST levels after psychological interventions ${ }^{13}$. If we consider that cognitive reserve is the result of the interaction between life exposures and genetic factors that operate together in the adaptation to brain diseases and aging ${ }^{33}$, among these genetic factors, REST could be having an important role.

In conclusion, while free serum REST levels may not be a viable $A D$ blood-based biomarker, ongoing research regarding REST in different blood components may yet yield an AD blood-based biomarker.

\section{ACKNOWLEDGMENTS}

This work was supported by CONACYT (grant 262295 to MATR). FLRC had a CONACYT Master's 
fellowship (596938). We thank all participants, as well as the Fundación para la Promoción Humana and Cree-Ser. We thank Dementia Laboratory researchers, Norma Serrano, Gabriela López, and María del Rocío Elizabeth Ortiz Butrón, for advice and technical support.

\section{REFERENCES}

1. Prince M, Wimo A, Guerchet M, Gemma-Claire A, Wu YT, Prina M. World Alzheimer Report 2015: the Global Impact of Dementia an Analysis of Prevalence, Incidence, Cost and Trends. London, United Kingdom: Alzheimer Disease International; 2015.

2. Knopman D. Clinical aspects of Alzheimer's disease. In: Dickson D, Weller R, editors. Neurodegeneration: the Molecular Pathology of Dementia and Movement Disorders. 2nd ed. Oxford, UK: Wiley-Blackwell; 2011. p. 39-50

3. Baird AL, Westwood S, Lovestone S. Blood-based proteomic biomarkers of Alzheimer's disease pathology. Front Neurol. 2015;6:236.

4. Snyder HM, Carrillo MC, Grodstein F, Henriksen K, Jeromin A, Lovestone $S$, et al. Developing novel blood-based biomarkers for Alzheimer's disease. Alzheimers Dement. 2014;10:109-14.

5. Lu T, Aron L, Zullo J, Pan Y, Kim H, Chen Y, et al. REST and stress resistance in ageing and Alzheimer's disease. Nature. 2014; 507:448-54

6. Orta-Salazar E, Aguilar-Vázquez A, Martínez-Coria H, Luquín-De Anda S, Rivera-Cervantes M, Beas-Zarate C, et al. REST/NRSFinduced changes of ChAT protein expression in the neocortex and hippocampus of the 3xTg-AD mouse model for Alzheimer's disease. Life Sci. 2014;116:83-9.

7. Baldelli $P$, Meldolesi J. The transcription repressor REST in adult neurons: physiology, pathology, and diseases. eNeuro 2015; 2:ENEURO.0010-15.2015.

8. Garcia-Manteiga JM, D'Alessandro R, Meldolesi J. News about the role of the transcription factor REST in neurons: from physiology to pathology. Int J Mol Sci. 2020;21:235.

9. Otsuki K, Uchida S, Wakabayashi Y, Matsubara T, Hobara T, Funato $\mathrm{H}$, et al. Aberrant REST-mediated transcriptional regulation in major depressive disorder. J Psychiatr Res. 2010;44:378-84.

10. Marullo M, Valenza M, Mariotti C, Di Donato S, Cattaneo E, Zuccato $C$. Analysis of the repressor element-1 silencing transcription factor neuron-restrictive silencer factor occupancy of non-neuronal genes in peripheral lymphocytes from patients with Huntington's disease. Brain Pathol. 2010;20:96-105

11. Goetzl EJ, Boxer A, Schwartz JB, Abner EL, Petersen RC, Miller $\mathrm{BL}$, et al. Low neural exosomal levels of cellular survival factors in Alzheimer's disease. Ann Clin Transl Neurol. 2015;2:769-73.

12. Winston CN, Goetzl EJ, Akers JC, Carter BS, Rockenstein EM, Galasko D, et al. Prediction of conversion from mild cognitive impairment to dementia with neuronally derived blood exosome protein profile. Alzheimers Dement (Amst). 2016;3:63-72

13. Ashton NJ, Hye A, Leckey CA, Jones AR, Gardner A, Elliott C, et al. Plasma REST: a novel candidate biomarker of Alzheimer's disease is modified by psychological intervention in an at-risk population. Transl Psychiatry. 2017;7:e1148.

14. Qian Li, Yang Y, Reis C, Tao T, Li W, Li X, et al. Cerebral small vessel disease. Cell Transplant. 2018;27:1711-22.
15. Hommet $\mathrm{C}$, Mondon $\mathrm{K}$, Constans $\mathrm{T}$, Beaufils $\mathrm{E}$, Desmidt $\mathrm{T}$, Camus $V$, et al. Review of cerebral microangiopathy and Alzheimer's disease: the relation between white matter hyperintensities and microbleeds. Dement Geriatr Cogn Disord. 2011 32:367-78

16. Gabryelewicz T, Styczynska M, Luczywek E, Barczak A, Pfeffer A, Androsiuk $W$, et al. The rate of conversion of mild cognitive impairment to dementia: predictive role of depression. Int ] Geriatr Psychiatry. 2007;22:563-7.

17. McKhann G, Knopman DS, Chertkow H, Hymann B, Jack CR Kawas $C$, et al. The diagnosis of dementia due to Alzheimer's disease: recommendations from the national institute on aging Alzheimer's association workgroups on diagnostic guidelines for Alzheimer's disease. Alzheimers Dement. 2011;7:263-9.

18. Folstein MF, Folstein SE, McHugh PR. "Mini-mental state". A practical method for grading the cognitive state of patients for the clinician. J Psychiatr Res. 1975;12:189-98

19. de Beaman SR, Beaman PE, Garcia-Peña C, Villa AM, Heres J, Córdova $A$, et al. Validation of a modified version of the minimental state examination (MMSE) in Spanish. Aging Neuropsychol Cogn. 2004;11:1-11.

20. Morris JC. The clinical dementia rating (CDR): current version and scoring rules. Neurology. 1993;43:2412-14.

21. Beck AT, Steer RA, Brown GK. Manual for the Beck Depression Inventory-II. San Antonio, TX: Psychological Corporation; 1996.

22. Jurado S, Villegas MA, Méndez L, Rodríguez F, Loperena V, Varea $\mathrm{R}$. La estandarización del inventario de depresión de beck para los residentes de la ciudad de México. Salud Ment. 1998; 21:26-31.

23. Sheikh JI, Yesavage JA. Geriatric depression scale (GDS) recent evidence and development of a shorter version. Clin Gerontol. 1986;5:165-73.

24. Fernández-San Martín MI, Andrade C, Molina J, Muñoz PE, Carretero $B$, Rodríguez $M$, et al. Validation of the Spanish version of the geriatric depression scale (GDS) in primary care. Int ] Geriatr Psichiatry. 2002;17:279-87.

25. Alexopoulos GS, Abrams RC, Young RC, Shamoian CA. Cornell scale for depression in dementia. Biol Psychiatry. 1988; 23:271-84

26. Fazekas F, Chawluk JB, Alavi A, Hurtig HI, Zimmerman RA. MR signal abnormalities at $1.5 \mathrm{~T}$ in Alzheimer's dementia and normal aging. Am J Roentgenol. 1987;149:351-56.

27. O'Bryant SE, Gupta V, Henriksen K, Edwards M, Jeromin A, Lista $S$, et al. Guidelines for the standardization of preanalytic variables for blood-based biomarker studies in Alzheimer's disease research. Alzheimers Dement. 2015;11:549-60.

28. Lowry OH, Rosenbrough NJ, Farr AL, Randall RJ. Protein measurement with the Folin phenol reagent. J Biol Chem. 1951; 193:265-75

29. Faronato M, Coulson J. REST (RE1-silencing transcription factor). Atlas Genet Cytogenet Oncol Haematol. 2011;15:208-13.

30. Huang Y, Potter R, Sigurdson W, Kasten T, Connors R, Morris JC, et al. $\beta$-Amyloid dynamics in human plasma. Arch Neurol. 2012; 69:1591-7.

31. Kuwahara K, Saito Y, Takano M, Arai Y, Yasuno S, Nakagawa Y, et al. NRSF regulates the fetal cardiac gene program and maintains normal cardiac structure and function. EMBO J. 2003 22:6310-21.

32. Martin D, Allagnat F, Chaffard G, Caille D, Fukuda M, Regazzi R, et al. Functional significance of repressor element 1 silencing transcription factor (REST) target genes in pancreatic beta cells. Diabetologia. 2008;51:1429-39.

33. Hahn C Lee CU. A brief review of paradigm shifts in prevention of Alzheimer's disease: from cognitive reserve to precision medicine. Front Psychiatry. 2019;10:786 